\title{
La neutralidad o la pérdida de la neutralidad en la Segunda Guerra Mundial. Cuestiones pendientes de un debate todavía inconcluso
}

\author{
Antonio Marquina Barrio
}

A juzgar por el éxito del sistema de desinformación instaurado por el régimen de Franco y por algunos de sus principales protagonistas acerca del papel de España y la política exterior española durante la Segunda Guerra Mundial, se podria decir que ciertos mitos han calado tan profundamente en el pensamiento colectivo que son muy difíciles de desarraigar. Estando ya en los cincuenta años del estallido de la Segunda Guerra Mundial podemos hacer un balance de qué tesis quedan imbatidas y qué asuntos habría que dilucidar para cerrar definitivamente la esclusa al torrente de desinformación que inundó la memoria colectiva española.

Podemos decir que el mito de la neutralidad española durante la Segunda Guerra Mundial, que fue puesto en entredicho por las Naciones Unidas con la condena del régimen de Franco en 1946, sobrevivió en buena parte gracias a la propia Guerra Fria. Curiosamente en los años sesenta, un conjunto de historiadores y biógrafos extranjeros apuntalaron el principal mito franquista de la Segunda Guerra Mundial, la resistencia de Franco en Hendaya y la Neutralidad española. George Hills, Brian Crozier $y$, en otro orden, Donald Detwiler, legitimaron esta mitologia. Recuerdo, en este sentido, la discusión mantenida con el profesor Detwiler en Washington en 1982 sobre este tema. Era convencido defensor de la política de neutralidad del general Franco.

El año 1978 supone un significativo punto de partida en la revisión de la política exterior española con respecto a Alemania durante la Segunda Guerra Mundial. Modestamente podemos decir que las líneas argumentales que entonces desarrollamos se han mantenido, abriéndose paso entre la maraña de descalificaciones y testimonios interesados. 
A solicitud del diario El País, donde habiamos publicado un breve trabajo sobre la Red TO de espionaje, hicimos un estudio de más de veinte folios con notas a pié de página que el diario publicó íntegramente los días 19, 21 y 22 de noviembre de 1978 con los siguientes títulos:

1. "Franco quiso entrar en la Segunda Guerra Mundial». "Hitler consideró innecesaria en 1940 la entrada de España en el conflicto europeo".

2. "Hitler y Mussolini deciden, antes de la entrevista de Hendaya, la no beligerancia de España».

3. «Para Hitler, la entrevista de Hendaya fue una trata de ganado de segunda categoria".

A esta revisión siguieron otros tres artículos de Ramón Serrano Súñer los días 26, 28 y 29 de noviembre con los siguientes títulos:

1. «Puntualizaciones sobre las relaciones de Franco y Hitler durante la Segunda Guerra Mundial».

2. "Ribbentrop acusó a un ministro español de estar al servicio de los ingleses".

3. "Hitler tenia minuciosamente planeado el ataque contra Gibraltar".

Luego se produjo una nueva réplica nuestra el 15 de diciembre de este mismo año titulada «Más datos sobre las difíciles relaciones entre Franco y Hitler en 1940"; consecuencia del juego del antiguo ministro de Asuntos Exteriores quien, en unas declaraciones al diario $Y a$, volvió a la carga contra nuestra revisión.

Como era de esperar, dada la psicología del ex-ministro, volvió a contestar el 23 de diciembre con un nuevo artículo titulado: «Mi punto final sobre Hendaya».

Tras este primer debate en profundidad, no exento de consecuencias extremadamente desagradables, las tesis renovadoras expuestas en nuestra investigación y aireadas por la prensa, han tardado en imponerse más de una década.

Los puntos centrales de esta revisión fueron expuestos, casi en el vacio en los primeros años, en diversas conferencias y, de forma especial, en las siguientes publicaciones:

1. El Plan Félix (Historia Universal 16, 1984).

2. Estudio preliminar al libro de L. Pascual, La planificación militar británica durante la Segunda Guerra Mundial (Madrid 1984).

3. "La relative neutralité espagnole» en Les états neutres européens et la Seconde Guerre Mondiale (Neuchatel, 1985). 
4. El impacto de la Segunda Guerra Mundial en Europa y España (Comunidad de Madrid, 1986).

5. España en la politica de seguridad occidental (1939-1986) (Madrid, 1986).

En 1980, Victor Morales Lezcano publicó su obra, Historia de la Nobeligerancia (Las Palmas, 1980), decantándose por la neutralidad española.

Curiosamente, en 1981 se produjo un intento de reboque de fachada en este tema con clara orientación de apuntalamiento de las tesis tradicionales. Este fue el trabajo de Ricardo de la Cierva, Hendaya, punto final (Barcelona, 1981).Tres años después apareció la obra de Luis Suárez, Francisco Franco y su tiempo, en ocho volúmenes, manteniendo férreamente la tesis tradicional y propagandística del régimen de Franco. Habrá que esperar a 1985 para encontrar una nueva aproximación renovadora sobre la política exterior de este período en la obra de Javier Tusell y Genoveva Garcia, Franco y Mussolini (Barcelona, 1985). Dos años después, la obra de Manuel Espadas, Franquismo y política exterior (Madrid, 1987) abordó este asunto sin romper de modo claro con la tesis de la neutralidad española.

En los últimos tres años han aparecido nuevas obras que, curiosamente, han silenciado en algunos casos estudios y debates mantenidos con anterioridad, aunque hayan seguido sustancialmente sus líneas argumentales, no aportando ningún otro argumento de fuerza realmente innovador.

Las tesis mantenidas podemos resumirlas asi:

1. Ni el general Franco ni sus colaboradores más inmediatos, ni especialmente Serrano Súñer tuvieron nunca la intención de meter a España en guerra al lado del Eje. Franco, entre julio y diciembre de 1940, logró -con medios muy débiles - imponer su decidida voluntad de no entrar en la guerra al lado del Eje 1.

2. Franco salió de Hendaya indemne, con ciertas promesas verbales y un consenso en continuar las negociaciones. Algunos escritores, empeñados en manchar la memoria de este éxito que, con otros varios, logró preservar a España de los horrores de la Segunda Guerra Mundial, insisten en que Franco quería ir a la guerra, pero los alemanes no le aceptaron. Esto es falso?

R. de la Clerva. Hendaya, Punto final, Barcelona, Planeta, 1981, pág. 168.

L. SuÁrez, Francisco Franco y su tiempo, Madrid, Fundación Francisco Franco, 1984, Tomo III, pág. 197. 
3. El general Franco y Ramón Serrano Súñer estaban completamente decididos a entrar en la guerra. Si este paso no se llegó a producir se debió, en buena medida, a la falta de insistencia que Hitler mostró en sus requerimientos (fruto de una concepción estratégica que rebajaba el papel de España) y por el alto precio territorial con el que los españoles pretendieron vender su beligerancia, muy por encima de su propia capacidad militar.

La firma del protocolo de Hendaya no supone un salto cualitativo sino que los nuevos compromisos son una consecuencia lógica según el curso que mantenían las relaciones bilaterales normales ${ }^{3}$.

4. Franco estaba ansioso de formar parte del nuevo orden mundial del Eje tras la caida de Francia en el otoño de 1940. El protocolo de Hendaya constituyó un compromiso formal por parte de España para entrar en guerra del lado del Eje ${ }^{4}$.

5. Si la España de Franco no entró en la guerra fue en gran parte debido a los propios Hitler y Mussolini. El primero insistió, entre agosto y diciembre, en la entrada española, pero sólo ofrecía a cambio Gibraltar porque no quería enemistarse con los franceses... Mussolini no hizo mucho para conseguir la intervención española, porque era lo mismo que ganarse un competidor ${ }^{5}$.

A nuestro juicio existen varios puntos vidriosos que cabe resaltar en el estado actual de la investigación ${ }^{6}$. Hagamos previamente una breve introducción. Antes de llegar al punto crucial de septiembre-octubre de 1940.

Una vez que se inicia la Segunda Guerra Mundial, España mantiene su status de neutralidad, aunque con una clara orientación favorable a Alemania. El gran problema surge cuando se produce la ofensiva alemana sobre Bélgica, Holanda, Luxemburgo y Francia. El 13 de junio, por decisión del Consejo de Ministros, España pasa de la Neutralidad a la No-beligerancia.Previamente Italia había entrado en la guerra, atacando a Francia. En esta situación de desmoronamiento de Francia y en vistas de una futura reordenación europea, Franco envía a Berlín al general Vigón,

\footnotetext{
pág. 199.

R. Garcia. Franquismo y Tercer Reich, Madrid, Centro de Estudios Constitucionales, 1994,

P. Preston, Franco, Barcelona, Grijalbo, 1994, pág. 490 y 495.

J. Tusell y G. Garcia, Franco y Mussolini, Barcelona, Planeta 1985, y J. Tusell, Carrero, Madrid, Temas de Hoy, 1993, pág. 39-40.

6 La puesta al dia más completa es el número monográfico de Guerres Mondiales et Conflicts Contemporains, № 158, y el vol. Il de la revista Espacio, Tiempo y Forma. Véase también J. TuSELL, “Cartas Secretas, Franco-Mussolini», Historia 16, 141 (1988).
} 
jefe del Alto Estado Mayor, para que las autoridades alemanas hicieran un sitio a las reivindicaciones españolas, que en este momento no se tomaron en consideración.

Es a partir de agosto cuando el asunto de las pretensiones españolas se dinamiza de nuevo, remitiéndose a Berlín por el embajador Stohrer un borrador de protocolo donde se solventaba la entrada en guerra de España, las ayudas económicas y militares y las reivindicaciones territoriales. Tanto la entrada en la guerra como la dirección de las operaciones militares eran competencia del estado español. Significativamente en el artículo XII se establecía la entrada en vigor del protocolo una vez que Italia diese su visto bueno a los dos gobiernos. Por ello, Franco escribió a Mussolini el 15 de agosto, solicitando su ayuda en la consecución de las reivindicaciones españolas.

Con anterioridad, en julio, Mussolini habia urgido a Franco a entrar en la guerra y conquistar Gibraltar, pues con la Roca en poder de los británicos les era imposible a los italianos actuar con éxito en el Mediterráneo.

Mussolini contestó el 25, señalando que si España no entraba en guerra daría la espalda a la Historia europea, resaltando que no podía esperar hasta el final, pues entonces no tendria posibilidad de obtener las reivindicaciones territoriales que deseaba. En uno de los párrafos, el Duce le indicaba que podía contar con la plena solidaridad de la Italia fascista.

Desde esta perspectiva, teniendo en cuenta el desarrollo de los bombardeos aéreos sobre el Reino Unido, hay que entender los planteamientos españoles.

Por su parte, Hitler conversó el 6 de septiembre con el almirante Raeder sobre la operación Seeloewe, sus costes y sus dificultades, siendo éste de la opinión de que Gibraltar y Suéz constituian objetivos de mayor entidad para la guerra, pues el control del Mediterráneo permitiría una importante aportación de materias primas, daría a Alemania una posición geoestratégica mejor, e impediría las actividades comerciales y militares británicas en el sur del Atlántico. Hitler entonces señaló que, si la operación Seeloewe no pudiera llevarse a efecto durante el invierno, la situación en el Mediterráneo tendria que aclararse.

Tres días después partió para España el general Von Richthofen, siguiendo una directiva de Hitler y Göring, y sondeó a Franco en San Sebastián. Este le manifestó que creía que los ataques aéreos acabarían con la resistencia británica en dos o tres semanas, pero al mismo tiempo mostró su preocupación por entrar en una guerra que fuese larga por el posible bloqueo. España necesitaba suministros alimenticios, combustible 
y materias primas. Von Richtofen manifestó que Alemania trataria de hacer frente a estas necesidades, pero dejaba a Franco el decidir su entrada en la guerra.

Cuatro días después emprendió viaje a Berlín una amplia misión española encabezada por Ramón Serrano Súñer. El objetivo secreto era sólo conocido por Franco y por Serrano Súñer. En efecto, antes de la salida de Serrano, había tenido lugar en San Sebastián una reunión bastante movida del Consejo de Ministros, a la que no asistió Beigbeder, donde Franco y Serano Súñer admitieron que la guerra no habia sido tan corta como esperaban, y que en vez de hacer una demostración de fuerza militar con respecto al Marruecos francés para la que se habían estado preparando, era mejor tratar de obtener esta reivindicación por medio de un acuerdo con Francia, tal como Rumania y Hungría habían hecho con Transilvania, notificándolo a las potencias vencedoras para que dieran su visto bueno. La mayoría de los demás ministros se habían mostrado escépticos, pero manifestaron que si Alemania estaba de acuerdo, España obtendría Marruecos y Orán, en cuya reivindicación existía unanimidad, si bien estuvieron de acuerdo en que Serrano Súñer no debía discutir ningún reajuste de relaciones con Alemania. Pero, como indicamos, Franco y también Serrano Súñer habian llegado a la conclusión de que la ofensiva aérea de Alemania acabaría con la resistencia británica en dos o tres semanas debiendo estar preparados para sentarse en la mesa de los vencedores y repartirse el botín. Pero Serrano Súñer no podia ofrecer la cooperación militar de España en la forma de una ocupación del Marruecos francés y un ataque a Gibraltar, aunque debía tantear el terreno y ver las posibilidades.

El ministro llevó consigo una carta de Franco a Hitler, fechada el 11 de septiembre en San Sebastián, en la que, tras expresar su amistad, procedía a presentar a su ministro, quien explicaría de forma más precisa lo que el general Vigón ya había manifestado anteriormente. La carta expresaba en su último párrafo la firme fe del general Franco en la inminente y final victoria de las armas alemanas.

No nos vamos a adentrar en el contenido de las conversaciones de Serrano Súñer en Berlín y Roma, que han sido suficientemente expuestas por diversos autores ${ }^{7}$. Lo que si vamos a señalar en este artículo son las diversas interpretaciones de los resultados de estas entrevistas. En

A. Marquina, "Franco quiso participar en la Segunda Guerra Mundial", El País, 19, 21 y 22 de noviembre de 1978; España en la politica de seguiridad occidental (1939-1986), Madrid, Ediciones Ejército, 1986, págs. 29 y Ss. J. TuseLL, G. GaACiA, Franco y Mussolini, Barcelona, 
principio cabe resaltar la admisión ya en las últimas obras publicadas de un factor esencial, el cambio de opinión de Hitler sobre la oportunidad de ceder a España el Marruecos francés, por miedo a desestabilizar la situación en la Francia de Vichy que, tras la resistencia al ataque en Dakar, consideró fundamental incluir en el nuevo orden europeo. Esto será decisivo y explica la preparación equivocada de la entrevista de Hendaya por parte de Serrano Súñer y de Franco y los resultados posteriores.

En segundo término, la admisión general del papel de Italia; las autoridades italianas consideraban que las reivindicaciones españolas entraban en conflicto con las aspiraciones italianas e influyeron en la decisión de mantener a España en reserva, considerando la no beligerancia más ventajosa que la intervención.

En tercer lugar, ligado con los dos puntos anteriores, la ausencia de presiones alemanas para que España entrara en la guerra. Sobre este punto existe también ya un consenso casi general.

Donde sí cabe señalar todavía diferencias es sobre los resultados de la entrevista de Hendaya. Prácticamente ningún historiador da importancia a los resultados, subrayando, eso sí, el fracaso de las ambiciones de las autoridades españolas, y en algún caso ${ }^{8}$ se ha llegado a sostener que la firma del protocolo de Hendaya no supone un salto cualitativo en las relaciones entre ambos Estados. Esta observación no es acertada. Basta con leer el protocolo para percatarse de que España se adhiere en este momento al Pacto de Acero, aunque quede pendiente la entrada en el Pacto Tripartito, en una fecha a determinar conjuntamente por los cuatro países y la entrada en la guerra contra el Reino Unido, una vez concedidos los apoyos militares y económicos necesarios.

El Pacto de Acero supone un reajuste fundamental en las relaciones de España con Alemania e Italia; basta con leer su articulado, en especial los artículos uno (contactos sobre todas las cuestiones relativas a intereses comunes), dos (consultas sobre medidas a adoptar para la tutela de sus intereses, y en caso de amenazas a la seguridad e intereses vitales de una parte, prestar pleno apoyo político y diplomático por la otra parte), tres (en caso de guerra -en la que ya se encontraban- de una parte, alianza inmediata de la otra y apoyo con todas sus fuerzas militares por

Planeta, 1985, págs. 103 y ss. Y más recientemente P. Preston, Franco, Barcelona, Grijalbo, 1994, págs. 472 y ss. R. Garcia, Franquismo y Tercer Reich, Madrid, Centro de Estudios Constitucionales, 1994, págs. 178 y ss.

8 R. Garcia, op. cit., pág. 199. 
tierra, mar y aire), cuatro (para cumplir el artículo tres, profundizar en grado superior su colaboración en el campo militar y en el campo de la economía de guerra así como contactos permanentes para adoptar las medidas necesarias para su aplicación y la creación de Comisiones Permanentes).

Esto y no otra cosa explica el salto cualitativo, jurídico, político y militar en las relaciones de España con Alemania e Italia, y las servidumbres consiguientes, profundización, ciertamente, de las relaciones que ya se mantenían con estos Estados desde la guerra civil.

Creer otra cosa sería algo asi, salvadas las diferencias, como creer que la entrada de España en la OTAN en 1982 no supuso un paso cualitativo de España en las relaciones con el mundo occidental, porque España ya tenía unos acuerdos de colaboración con los Estados Unidos que la implicaban en una serie de campos de seguridad y defensa.

Esta minusvaloración del Pacto de Acero, que afectó cualitativamente a la colaboración entre policías, Estados Mayores, servicios de información - colaboración que ya venía de años atrás- y acuerdos económicos, perdura, como indicamos, en la actualidad en prácticamente todos los estudios realizados y anteriormente citados. Se sigue hablando de «neutralidad benévola».

Otro aspecto significativo sobre el que las interpretaciones no han sido completamente coincidentes es el intento de reapertura del proceso negociador con la carta de Franco a Hitler, fechada el 30 de octubre y entregada en Berlin el 3 de noviembre.

Para la mayoría de los investigadores, la postura de Serrano Súñer en Berchtesgaden fue claramente dilatoria frente a un Hitler, que apremiaba con urgencia la entrada de España en la guerra.

La cuestión que, a nuestro juicio no está clara, en función de la minuta de la entrevista de Serrano Súñer con Von Ribbentrop y de las informaciones que llegaron a la embajada británica en Madrid, es hasta dónde llegaba el interés español por conseguir los territorios que habian quedado indeterminados en el protocolo de Hendaya. Nosotros mantuvimos en 1978 la tesis de que Serrano Súñer presiona también intentando hacer ver la importancia que todavía tenía el Reino Unido, frente a las seguridades que los dirigentes alemanes tenían en su derrota, la importancia atribuida al papel de España no había variado en exceso ni tampoco se admitian hechos consumados. Se daba un tiempo para la preparación de la operación, donde el peso sería llevado por las fuerzas alemanas y para la firma por España del Pacto Tripartito. Lo que parece 
fantástico es afirmar, tras la firma del protocolo con la adhesión de España al Pacto de Acero, sin contemplaciones, que si Hitler hubiera ordenado la realización de la operación se hubiera producido una resistencia por parte española, o que Canaris jugó un papel decisivo para impedir esta operación, cuya racionalidad, a nuestro juicio, no puede considerarse desde nuestra óptica actual, sino desde la óptica de las prioridades de los dirigentes alemanes de entonces. En función de estos compromisos, dada también la situación económica y militar española, la negativa española a embarcarse en la guerra con la firma del Pacto Tripartito, al no haberse aclarado las compensaciones territoriales, era un obstáculo que desequilibraba la balanza y hacía más ventajoso mantener a España fuera de la guerra. Esto, a pesar del voluntarismo e irritación que Hitler manifestó en ocasiones.

Otro asunto ligado con el anterior es si el gobierno español o, más en concreto Franco, estuvo posteriormente dispuesto a la firma del Pacto Tripartito. Hoy en día se producen todavía notables silencios sobre este asunto ${ }^{9}$. Sin embargo es un asunto que ya venía señalando desde hacía tiempo ${ }^{10}$. Es precisamente en abril y mayo de 1941 cuando España estuvo más cerca de firmar el Pacto Tripartito.

El 28 de abril, el Ministerio de Marina español dictó una orden secreta a los barcos mercantes españoles para que, en caso de que España entrara en guerra, se dirigieran a determinados puertos. La razón no era otra que los cambios que se estaban produciendo en el Mediterráneo Oriental ${ }^{11}$.

Es precisamente en este momento cuando la presión de la Junta Militar, apoyada económicamente por el Reino Unido, se hace sentir, induciendo un cambio ministerial con la entrada del coronel Galarza en el Ministerio de la Gobernación, y otros nombramientos, con una mayor división y enfrentamiento entre militares y falangistas. Esto, que aparentemente podía impedir una decisión sobre la firma del Pacto Tripartito, al carecer de la cohesión y la unanimidad necesaria, implicó por el contrario una huida hacia delante de Serrano Súñer ante la pérdida notable de su poder político y viendo en la entrada en la guerra una oportunidad para cohesionar el país y sacar adelante su proyecto político totalitario. La

\footnotetext{
9 Véase por ejemplo P. Preston, op. cit., capitulo 17.

10 Véase por ejemplo, J. Tusell y G. Garcia, Franco y Mussolini, Barcelona, Planeta, págs. 138 y ss.

11 Véase A. MARQuINA, "L' etape de Ramón Serrano Súñer au Ministère des Affaires Etrangeres", en Guerres Mondiales et Conflicts Contemporains, vol. 158, pág. 19.
} 
situación alimenticia había mejorado y Creta fue conquistada por los alemanes a finales de mayo. El Mediterráneo aparecía como el centro de operaciones del Eje. Serrano Súñer, el 9 de junio, en su contestación a una carta de Ciano, tras una larga conversación con Franco se mostró favorable a que España se adhiriera públicamente al Pacto Tripartito, bastando una carta privadísima de los dirigentes del Eje que les diera seguridades sobre las reivindicaciones territoriales que habian venido solicitando.

Afortunadamente el 22 de julio se producia la operación Barbarroja que hizo variar el eje de atención bélico hacia el Este de Europa. A partir de este momento las posibilidades de firma del Pacto Tripartito desaparecieron, incrementándose notablemente la división entre militares y falangistas. Posteriormente la entrada de los Estados Unidos en la guerra volvió más cautelosos a los dirigentes españoles.

En conclusión, cabe señalar que los principales hitos del proceso de "marcha hacia la guerra" de los años 1940-1941 están ya establecidos, aunque todavía subsistan silencios poco comprensibles. Quedan, no obstante, aspectos significativos a clarificar, que darán en su momento, cuando finalmente se abran determinados archivos, una mayor dimensión al significado de la adhesión de España al Pacto de Acero, de forma especial las conexiones entre los Estados mayores, Servicios de Información, o las conexiones entre la Gestapo y la policía española que se estrecharon con la visita de Himler a Madrid. Falta también un estudio monográfico sobre las relaciones entre los partidos afines.

Podemos además señalar que, una vez establecidos estos hitos, queda por clarificar otro importante asunto, el papel en el proceso decisorio de la política exterior de los distintos actores. Los estudios actuales son insuficientes a este respecto. Está ya suficientemente clarificada la percepción equivocada de Franco en el momento de la "gran tentación", pero sería útil o más bien necesario, un estudio pormenorizado de las imágenes del grupo dirigente español y sus percepciones sobre el significado de la evolución de los acontecimientos, así como su visión del papel español. Esto clarificaría significativamente el panorama historiográfico. Queda también pendiente de realización estudios monográficos sobre relaciones económicas de España con los principales estados participantes en la guerra. Monografías como la de Rafael García muestran los vacíos que se pueden llenar con estudios de este tipo. 